\title{
Indian Dental Workforce: The Need of Getting It Back to Action
}

\section{VAPNINDER KAUR}

India encounters a severe gap in the number of working dental professionals to that required. Population explosion and development are on the peak whereas good dental health is lacking behind. India has got numerous dental institutions, governing dental bodies, established dental associations but inadequate dental workforce, poor health literacy and substandard oral health status. This obviously implies that we are somewhere something is going wrong that is hindering the country from achieving the Millennium Development Goals. The need of the hour is to focus on the concerned issues, formulation of fool proof policies and strategies, strengthening oral health education and implementation of oral health programs with continuous surveillance.

KEYWORDS: Dental Workforce, Dentist Population Ratio, Dental Health

\section{INTRODUCTION}

India is the second most populous country of the world with fastest developing economy. The development speeding up at a high pace is majorly technological, with less stress on improvement in health sectors. Every financial year, a new budget is set up with minimal focus on overall health and negligible on dental health. The country has more then 300 well established dental institutes but still there is minor improvement in oral health status of the countrymen. A report by World Health Organization in 2006 stated that India has only $0.06 \%$ dentists per 1000 population pointing to a drastic shortfall of dentists. ${ }^{1}$ A study conducted by Halappa et al in 2014, found these statistics to be o.o88 per 1000 population. ${ }^{2}$

Majority of Indian population, around $68.84 \%$ is residing in rural areas as per the 2011 census $^{3}$ but most of the dental professionals are reluctant to work there. In the year 2004, India had a dentist to population ratio of 1:1000o in urban areas and around 1:2500oo in rural areas. ${ }^{4}$ From 2004 to 2014, the overall dentist to population ratio has improved from 1:30000 to 1:10271. ${ }^{4,5}$ But still it's the people residing in urban regions who are enjoying this privilege. Between 1991 and 2013, The admissions to dental colleges has exponentially increase from 3100 in 1991 to 23800 in $2013 .{ }^{6}$ The number of dental institutes in India has also increased crossing a total of more than 300 but there is a gross inequality in their distribution among different states with Karnataka having more than 40 and some states with no dental college. Growth in number of government colleges is stagnant while private colleges have sprouted like anything and their number has increased up to four times as compared to government dental colleges. ${ }^{4}$ With such a big number of institutes and thousands of students getting enrolled each year, no significant improvement in dentist to population ratio, especially in the rural areas is questionable. Vatsul Sharma et al. conducted a study on dental interns and found out that $55.95 \%$ of the subjects were willing to serve in rural areas. ${ }^{7}$ Countless factors govern the decision to serve in rural areas. For those not opting for postgraduation, tough working conditions in rural areas, no scope for professional future, poor living conditions, isolation and lack of recreation were reported to be the main reasons of reluctance in literature. ${ }^{7}$

Dentistry in India is not a subject of choice anymore and many of the aspirants opt for dentistry when they do not get admission into MBBS course. The fee structure of the management seats is also quite high when compared to dental colleges. When admission into BDS is treated as an option, development in lack of interest becomes obvious in the dental practice. ${ }^{8}$ Despite numerous dental colleges with thousands of new admissions every year, there is an acute shortage of dentists. The question here arises is that where did they all go?

The attrition rate of dentists is India is going higher. Countless have waved a goodbye to this noble unrestricted use, distribution and reproduction in any medium, provided the use is not commercial and the original author(s) and source are cited. 
profession. But blaming them for the same cannot be justified. The vacancies for dentists, both in central and state government sectors are meagre, may be due to the fact that no special allocation from the budget is given to oral health. Moreover, escalating corruption and malpractices mask the selection procedure for such posts. ${ }^{9}$ Immigration to developed countries is an upcoming practice these days. Very few seats in dental postgraduate programs, financial benefits, good standards of living and quality of life and fulfilment of personal aspirations are the major possible reasons behind this brain drain which is leading to a sheer wastage of brilliant talent which otherwise could have been used for the welfare of the nation. Such movements are also progressing within the country where most of the dentists are moving to major towns and cities seeking better employment opportunities which furthers disrupts the balance of the dentist to population ratio. Low paying capacities of people residing in rural areas also pushes the dental professionals to move towards the urban side. Production and maintenance of a rich-quality workforce has also become a challenging issue mainly due to privatization of colleges. Due to a growth in these money-making institutions, the quality of dentistry has been hampered and the true essence of dentistry has vanished with a slow but visible decline in the ethical principles and moral values. A few students just get admission for the sake of improving their profile for matrimonial purposes and never continue with the profession.

Low salary with negligible increments has also impacted the dental profession a lot. Private institutions are paying shameful salaries to dental professionals at MDS level, even that too is late by a few months. Along with this, the college management uses them for their own benefits, pressurizing them for getting new admissions to college and engaging them in petty odd jobs.

Setting up a dental practice is the most common trend, but high investment for a posh set up, sky high costs of rental spaces or properties for clinics in good areas, lack of trained assistants, poor oral health literacy leading to unconcerned attitude towards oral health, belief of general population in old quacks rather then young qualified professionals, cost of dental treatments, unethical practices by other colleagues and violence against health professionals are the major hurdles one has to cross before establishing well as a private practitioners. This is a time intensive procedure and requires a lot of patience, which is somewhat lacking in the current generation.

Many dental graduates look for career options other than practicing dentistry. The most common these days are getting admission into master's in business administration, health administration or public health, overtaking non-medico family businesses and working with corporate pharmacovigilance firms, medical writing companies and pharmaceutical industries.

In India, dental health services are offered only by dentists due to lack of auxiliaries. Majority of these dentists' practice in towns and cities, treat the elite and well-off chunk of the urban population. The shortfall of dentists is mainly for the people from rural areas and the poor ones residing in urban and sub-urban regions. No separate budget allocation for oral health, absence of a primary health care approach, lack of oral health programs that are community oriented, mushrooming of private dental institutions are the major issues behind the unfortunate situation of dentistry in India. If the current situation continues, it will further lead to wastage of qualified dental manpower and create a menace to the ethical morality of the dental professionals.

As India is struggling to achieve a universal health coverage, it is important to reinforce the delivery of oral health care by well qualified and thoroughly trained dental professionals. The need of the hour is to understand the situational dilemma of dental professionals as this may prove of critical importance in the development of fruitful policies. There is also a need for a systematic human resource management system to ensure that the inequality between dentist to population ratio is eradicated. The skewed distribution of dentists between urban and rural regions in India need to be addressed. Implementation and monitoring of programs concerning oral health literacy would also be of much help in minimising social inequalities. The reasons behind the maldistribution of dental professionals should be thoroughly investigated and an effort to draft strategies to correct this disturbed equilibrium 
should be brought into action.

\section{REFERENCES}

1.World Health Organization. The world health report 2006 - Working together for health. Geneva, World Health Organization. 2006. Available from: www.who.int/whr/2006/whro6 en.pdf. [Last accessed on $29^{\text {th }}$ May 2019].

2. Halappa M, Naveen BH, Kumar S, Sreenivasa H. SWOT analysis of dental health workforce in India: A dental alarm. J Clin Diagn Res 2014;8 (11):ZEo3-05.

3. http://www.censusindia.gov.in. [Last accessed on 29 June 2019].

4. Tandon S. Challenges to the oral health workforce in India. J Dent Educ. 2004;68(7):28-33.
5. Vundavalli S. Dental manpower planning in India: Current scenario and future projections for the year 2020. Int Dent J 2014;64:62-7.

6. Dental Council of India. Available from: http://www.dciindia.org/ [Last accessed on 29 June 2019].

7. Sharma V, Gupta N, Rao NC. Perception towards serving rural population amongst interns from dental colleges of Haryana. J Clin Diagn Res 2014; 8(9): ZC31$\mathrm{ZC}_{32}$.

8. Dagli N, Dagli R. Increasing unemployment among Indian dental graduates - High time to control dental manpower. J Int Oral Health 2015;7:i-ii.

9. Yadav S, Rawal G. The current status of dental graduates in India. Pan Afr Med J 2016 Feb 1;23:22.
Source of support: Nil, Conflict of interest: None

\section{AUTHOR AFFILIATIONS:}

BDS, Private Practitioner

\section{Corresponding Address:}

\# B-407

Street no. 2,

Hazoor Singh Colony

Fazilka

Punjab

Kaurvap[at]gmail[dot]com
Cite this article as:

Kaur V. Indian Dental Workforce: The Need of Getting It Back to Action. Int Healthc Res J. 2019;3(4):138-140. https://doi.org/10.26440/IHRJ/0304.07260 